\section{Estudo \\ CoDebate}

em CAStão

Plamejamento
Revista Estudo \& Debate, Lajeado, v. 26, n. 3, 2019. ISSN 1983-036X

DOI: http://dx.doi.org/10.22410/issn.1983-036X.v26i3a2019.2102

\title{
DETERMINANTES E CONDICIONANTES DA DECISÁO DE COOPERAR AO NÍVEL LOCAL: UM ESTUDO DE CASO NA COMUNIDADE INTERMUNICIPAL DA REGIÃO DE COIMBRA
}

\author{
Pedro Miguel Alves Ribeiro Correia ${ }^{1}$, Ireneu de Oliveira Mendes², \\ Vanessa Medeiros Ribeiro ${ }^{3}$
}

\begin{abstract}
Resumo: $\mathrm{O}$ presente estudo visa explorar os determinantes e condicionantes que norteiam as cooperações intermunicipais e a diversidade de agentes e fatores que envolvem essa relação de cooperaçáo ao nível local na Comunidade Intermunicipal da região de Coimbra (CIM), Portugal. Objetivando conhecer o nível de cooperação entre os entes de esfera municipal a nível local na Comunidade Intermunicipal da Regiáo de Coimbra, foi elaborado um modelo inicial de pesquisa baseado no referencial teórico abordado, e aplicou-se um questionário a todos os municípios integrantes da CIM, para aferir qual a percepçáo dos trabalhadores dos diferentes municípios da região sobre a importância dos processos de cooperaçáo e sobre os fatores potenciadores dessa cooperaçáo local. Os dados recolhidos foram analisados com recurso a um modelo de equaçôes estruturais. Como conclusão, é possível afirmar que as percepçóes dos respondentes acerca das dimensôes "Motivação interna para cooperar" e "Rede de relaçóes entre agentes públicos" têm impacto direto e positivo nas suas percepções relativamente à Eficiência na alocação e Gestão dos recursos.
\end{abstract}

Palavras-chave: Cooperação Intergovernamental, Cooperaçấo Municipal, Determinantes da Cooperação, Fatores Condicionantes da Cooperação.

1 Doutoramento em Ciências Sociais (Especialidade em Administração Pública), Universidade Técnica de Lisboa (UTL). Licenciatura em Estatística de Gestão de Informaçáo, Universidade Nova de Lisboa (NOVA). Professor no Instituto Superior de Ciências Sociais e Políticas (ISCSP), Universidade de Lisboa (ULisboa). Vice-Presidente e Investigador Integrado do Centro de Administração e Políticas Públicas (CAPP), ISCSPULisboa. Investigador Colaborador do Centro Interdisciplinar de Estudos de Género (CIEG), ISCSPULisboa. Colaborador Estrangeiro do Grupo de Pesquisa em Administração da Justiça, Universidade de Brasília. Coordenador do Observatório Nacional de Administraçáo Pública (ONAP), ISCSP-ULisboa. Consultor para a Área de Planeamento e Política Legislativa da Direção-Geral da Política de Justiça (DGPJ) do Ministério da Justiça de Portugal.

2 Professor Auxiliar convidado do Instituto Superior de Ciências Sociais e Políticas (ISCSP) da Universidade de Lisboa (ULisboa). Assistente convidado da Faculdade de Direito da Universidade de Coimbra. Doutorando em Administração Pública no Instituto Superior de Ciências Sociais e Políticas da Universidade de Lisboa.

3 Mestre em Administração Público Privada pela Faculdade de Direito da Universidade de Coimbra. 


\title{
DETERMINANTS AND CONSTRAINTS OF THE DECISION TO COOPERATE AT THE LOCAL LEVEL: A CASE STUDY IN THE INTERMUNICIPAL COMMUNITY OF THE REGION OF COIMBRA
}

\begin{abstract}
The present study explored the determinants and constraints that guide the Intermunicipal Cooperations and the diversity of agents and factors that are involved in the relationship of cooperation at the local level of the Intermunicipal Community of Coimbra (IMC), Portugal. With the aim of knowing the level of cooperation between authorities at the local level of the Intermunicipal Community (IMC) in the region of Coimbra, an initial research model was elaborated based on a theoretical reference-approach, and a questionnaire was sent to all workers of the IMC. The purpose was to measure their perception on the importance of cooperation processes and the factors that enhance cooperation al the local level. The data collected were analyzed using a structural equation model. As conclusion it is possible to affirm that the perceptions of the respondents about the dimensions "Internal motivation to cooperate" and "Network of relations between public agents" has direct and positive impact on their perceptions regarding the "Efficiency in the allocation and Management of the resources".
\end{abstract}

Keywords: Intergovernmental Cooperation, Municipal Cooperation, Determinants of Cooperation, Factors of Cooperation.

\section{As relaçóes de cooperaçáo intermunicipais}

Entende-se ser de extrema importância no âmbito da Administração Pública a necessidade de colaboração entre os atores locais, devido às dificuldades enfrentadas por estes para sanar as penúrias que incorrem na administração pública no aspecto financeiro.

Segundo a literatura, um dos fatores que induzem a cooperação é a interdependência entre os municípios, que implica em um alto grau de dependência entre os governos locais, tornando difícil a tarefa de articular o exercício de funçôes públicas de interesse comum a um conjunto de unidades político-administrativas (municípios) (NIERO, 2011).

Conforme sublinha Niero (2011), gerir estas relações de interdependência entre os governos locais, significa que os problemas de interdependências entre as unidades políticoadministrativas autônomas na esfera local sejam tratadas de forma específica e organizada num mesmo nível. Essas interdependências estão conectadas por sua vez, às externalidades positivas e negativas na provisão dos bens e serviços públicos.

Afonso e Fernandes (2005), afirmam que os atores que tendem a participar de acordos de cooperação, são entidades que se dedicam à promoção do desenvolvimento, e dessa forma podem influenciar, financiar e implementar as políticas de cooperação que objetivem o desenvolvimento socioeconômico dos países, regióes e comunidades com maiores necessidades.

\section{Cooperaçáo e coordenaçáo}

A necessidade de cooperação e de coordenação são os elementos principais para o início de qualquer relação intergovernamental, seja qual for o interesse em comum que os entes tenham de forma independente ou conjunta.

$\mathrm{Na}$ busca pela satisfação das necessidades dos cidadãos, a rede de cooperação passou a crescer em âmbito global, mas principalmente intermunicipal. 
As relaçóes entre governos locais baseadas no princípio da coordenação devem ser compatíveis com a autonomia local, ou seja, a coordenaçấo das relaçóes intergovernamentais precisam respeitar a autonomia dos entes coordenados (NIERO, 2011).

A coordenação para alcançar economias de escala motiva as colaboraçóes regionais porque cada participante se beneficia. Porém, segundo Feiock (2009), quando um grande investimento em infraestrutura é necessário, podem ocorrer problemas entre os entes envolvidos desde a deserçáo ao longo do processo cooperativo e descumprimento das estratégias previamente fixadas, até os riscos dos custos de transação da cooperação.

Analisando os problemas de coordenação existentes, segundo Gulati e Singh (1998) estes surgem em detrimento da complexidade da interconexão entre tarefas envolvidas no processo, onde a incerteza e a informaçáo incompleta aumentam os problemas de coordenação entre os membros.

Já no que tange os problemas de divisão dos benefícios, estes existem quando é difícil para os agentes concordarem sobre quanto cada um receberá em funçáo do investimento realizado no acordo cooperativo, e a superaçáo desses problemas associados à distribuição dos ganhos mútuos dá origem a um processo de negociação altamente disputado e não menos estimulante de cooperação (HECKATHORN, D. D.; STEVEN, 1987).

Para tanto, por definição de cooperação temos a concepção de Afonso (1996, p. 30), onde apregoa que a cooperação intermunicipal corresponde a "uma forma de cooperação descentralizada na qual os municípios envolvidos assumem uma funçáo de participação ativa dos processos de desenvolvimento".

O desenvolvimento local na medida em que se torna parte de um projeto maior que engloba outros atores no mesmo contexto, é fundamental que tal projeto possua uma intervenção multidimensional (FERNANDES, 2012).

Feiock e Scholz (2013) sugerem que a gama de instituiçōes que surgiram para mitigar os problemas regionais de ação coletiva institucional, pode ser melhor compreendida de acordo com o grau de autonomia que os mecanismos proporcionam aos atores locais. Além disso, as ferramentas variam consoante se concentrem em relaçóes multilaterais coletivas ou em troca bilateral individual em redes.

Os problemas urbanos são de modo inerente problemas de ação coletiva e diante dos dilemas da açấo coletiva, os governos locais devem decidir se cooperam com os demais governos e as formas como essa cooperação se dará, ficando evidente a escolha do caráter da governança intermunicipal (FEIOCK, 2009).

Independentemente do nível de cooperação que seja planejado ou executado e quais os entes estejam envolvidos no respectivo projeto, a inovação e a cooperação em pequena escala criam normas de reciprocidade que facilitam açóes maiores e constroem uma identidade coletiva (OSTROM, 1998).

A coordenação emana de uma relação assimétrica entre o ente coordenador e o ente ou entes que coordena. Portanto, tem-se uma situaçáo de hierarquia entre um agente coordenador e os agentes coordenados. 
Conforme apregoa Rodriguez (2002, p. 7), em todo procedimento de coordenação legalmente estabelecido "é necessária a existência de cooperação sem a qual seria impossível estabelecer qualquer mecanismo de coordenaçáo", e ainda salienta o autor que "apesar da existência de mecanismos de sanção que obrigam o seu estrito cumprimento, a cooperação sem coordenação resultaria, sem nenhuma dúvida, não frutuosa” (RODRIGUEZ, 2002, p. 7).

É perceptível uma estreita relação entre os termos, uma vez que uma não pode existir sem a outra. A coordenação por um lado pressupóe a existência da cooperação e a cooperação por outro lado, necessita de mecanismos de coordenação, associados a comprometimento e coerência das açóes entre os agentes.

\subsection{Fatores condicionantes da cooperaçáo intergovernamental}

Quando se fala de cooperação intergovernamental, entende-se que muitos elementos envolvem a estrutura desenvolvida para o objeto em questão, e muitos são os fatores que induzem cada um dos entes públicos autônomos a abdicar de uma parcela da sua autonomia com vista a um objetivo único global de um grupo de outros entes autônomos.

Sob a perspectiva de Lynn et al. (2000, p. 235), a governação diz respeito "aos meios para alcançar a direção, o controle e a coordenação dos indivíduos ou organizaçóes total ou parcialmente autônomos em favor dos interesses em conjunto".

A governação portanto, depende da capacidade do governo e do setor público em "implicar e comprometer todos os parceiros numa tomada de decisão consensual destinada à promoção da ação coletiva em busca de fins comuns” (ANSELL; GASH, 2008, p. 546).

Nos quesitos de provisão de bens e serviços públicos bem como no planejamento estratégico, a cooperação é vista "como uma forma de lidar com economias de escala e eficiência na prestação de serviços públicos” (KETTUNEN, P.; TELES, 2015, p. 2).

As concepções quando se trata de cooperação, conforme Kettunen e Teles (2015) são de que existem duas abordagens de acordos voluntários de cooperação realizadas entre autoridades locais de baixo para cima. Sendo que tais abordagens não são "mutuamente exclusivas, uma vez que nos mesmos casos, ambas as experiências podem acontecer quase simultaneamente, embora assumindo formas jurídicas diferentes" (KETTUNEN, P.; TELES, 2015, p. 2).

Como uma iniciativa vinda de baixo, ou seja, por manifestação de interesses diretos dos municípios, tais relaçóes podem ser definidas e criadas de diversas formas como bem salienta Hulst et al. (2009, p. 264) quando menciona que tais arranjos "variam em sua composição, seu escopo e o grau de organização/integração".

Essa interação de diferentes governos e estruturas administrativas, chamada de Teoria da Gestão Pública (TGP), enfatiza a dispersão do poder, postura contrária ao modelo hierárquico, linear, integrado, típico da produção em massa; salienta a necessidade de coordenação das entidades que desenvolvem o processo de políticas públicas; baseia-se na criação de fortes redes de relação e parcerias; aloca na troca de recursos entre parceiros a razão de ser das redes; ressalta a confiança e a estabilidade contratual como critérios de sucesso; 
faz sobressair a importância das organizações sociais na solução de problemas sociais, onde nem o Estado nem o mercado dáo resposta por si sós ou conjuntamente (BILHIM, 2017).

Ademais, a cooperação se caracteriza por uma troca de interesses entre os participantes, e fatores como o tamanho ou os recursos insuficientes para prestar serviços ou cumprir obrigaçóes é um dos fatores contribuintes para tal processo (KETTUNEN, P.; TELES, 2015).

Assim, segundo Niero (2011), dois são os focos de análise, os motivos ou interesses dos gestores públicos na direção da colaboração intergovernamental e os custos (ou barreiras) imanentes à constituição do acordo de cooperação.

Existem quatro grandes argumentos a favor da cooperação intermunicipal, resultantes de diferentes referenciais teóricos: o modelo de economia política; a abordagem da teoria de redes; o argumento da escolha pública e a abordagem da açâo coletiva, segundo o que entendem Kettunen e Teles (2015).

Dentre estes, o primeiro fator considera os agentes locais como uma forma de eficiência econômica quando decidem fazer dos acordos de cooperação formas de driblar as externalidades e aumentar sua capacidade financeira em conjunto com outros agentes locais.

A teoria das redes por sua vez, utiliza da boa governança e do compartilhamento de recursos e ações uma forma de cooperação bem sucedida, onde e quando esta relação de confiança permite que sejam realizados tais contratos, sejam eles formais ou informais de cooperação objetivando de forma conjunta a diminuição dos custos e os obstáculos existentes para a formação de alianças de cooperação (KETTUNEN, P.; TELES, 2015).

O terceiro ponto a que os autores Kettunen eTeles (2015) se referem é a escolha pública onde fazem uso das palavras de Bouckaert et al. (2002) ao parafrasear que tal argumento reacende a questáo do debate sobre a complexidade da governança local contemporânea e seus inúmeros arranjos interinstitucionais e seus instrumentos organizacionais que se sobrepóem a prestação de serviços públicos e privados, leva a considerá-la como um sistema integrado de múltiplas unidades.

Em quarto e último lugar, a teoria da ação coletiva explica como funcionam as redes de cooperaçáo e Feiock (2009) salienta que os problemas urbanos sáo de modo inerente problemas de ação coletiva e diante dos dilemas da ação coletiva, os governos locais devem decidir se cooperam com os demais governos, as formas como essa cooperação se dará e os múltiplos arranjos de cooperação possíveis de serem utilizados pelos governos locais, fazendo alusão direta a colaboraçáo e disseminação da vontade dos municípios de cooperarem entre si, para que desta cooperação resultem esforços conjuntos e resultados para todos os envolvidos.

A Ação Coletiva Institucional (ACI), abordada por Feiock (2007), enfatiza a forma como os agentes públicos locais percebem e avaliam os custos e os benefícios que derivam da decisão de cooperar. Muito embora seja inegável que a cooperação intergovernamental produza elevados benefícios para aqueles que se dispóem a participar dos processos de cooperação, os agentes públicos também analisam que os custos podem superar os potenciais benefícios. 
Portanto, a forma de alocação desses custos, dependerá das regras em que o acordo foi previamente estabelecido, como afirma o autor, sendo as características dos serviços objeto da cooperação as "características econômicas, demográficas, sociais e geográficas das comunidades, as configuraçóes das instituiçóes políticas e a rede de relaçóes entre os agentes oficiais" (FEIOCK, 2007, p. 48).

O capital social é um recurso crítico para resolver problemas de coordenação e cooperaçáo, reduzir os custos de transação e facilitar o progresso do fluxo de informação entre os indivíduos em comunidades ou organizaçôes (FEIOCK, 2009).

Um dos principais fatores contextuais condicionante da cooperação se trata da localizaçáo geográfica. Os vizinhos têm incentivos para cooperar com base nos custos técnicos de compartilhamento de serviços. Para serviços com altos custos de transação, podemos esperar que um acordo seja solicitado com o mesmo vizinho em diferentes serviços. As fronteiras geográficas fixas também exigem repetição entre as jurisdiçôes vizinhas e, assim, reduzem os custos de transação criando interdependências (FEIOCK, 2009).

Morgan e Hirlinger (1991) apontaram para o fato de que governos locais situados em aglomeraçôes urbanas têm maior probabilidade de se envolver em acordos de cooperação.

Para Kettunen e Teles (2015), áreas urbanas, de fronteiras e rurais interferem na forma como são realizados os acordos de cooperação, bem como outros fatores como riqueza disponível ou capital social do município, tradiçóes, lideranças políticas, o planejamento existente e outros fatores ambientais afetam diretamente as formas de estrutura de cooperação.

Dentre todos os fatores apontados pelas pesquisas anteriores, a racionalização de recursos é ainda o maior e principal quesito motivador para que o município adote a solução da cooperação intermunicipal. Percebe-se, no entanto, um elevado grau de pragmatismo que orienta a ação dos gestores públicos, sendo necessário refletir se esse aspeto que estimulou a construção da cooperaçáo intermunicipal será suficiente para garantir a sustentabilidade desses consórcios públicos municipais ao longo do tempo (ABRUCIO; FILIPPIM; DIEGUEZ, 2013).

Para Hawkins (2011), os municípios de maior porte, ou seja, com maior população, possuem base fiscal e acesso ao mercado de capitais para levantar fundos e ofertar serviços com custos operacionais reduzidos. Ao contrário, os pequenos municípios, náo têm base populacional, assim como não possuem base fiscal e acesso ao mercado de capitais.

A estrutura de relaçóes formais e informais entre os agentes públicos locais é um facilitador da troca de informações e permite uma maior credibilidade às promessas dos agentes.

Nas palavras de Feiock (2007, p. 56), quando se fala em instituiçóes políticas, e estas passam a criar "um horizonte temporal de longo prazo, os ganhos de curto prazo são contrapostos aos ganhos de longo prazo advindos da cooperação continuada".

Ainda de acordo com este autor manutenção da orientação para políticas de cooperação continuada, por parte dos "executivos e do corpo administrativo, reduz a 
incerteza e cria-se um ambiente de decisão focado no longo prazo e na consideração dos benefícios coletivos e seletivos da cooperação".

Vê-se a cooperação como um vislumbre das potenciais capacidades que o Estado pode atingir quando trabalha em conjunto e várias são as formas que esta cooperação pode ocorrer dentro da estrutura administrativa, para tanto, compreender mais sobre o âmbito em que a cooperação é realizada permite compreender de forma mais abrangente o foco e o objetivo da cooperação.

Os mais diversificados tipos de serviços e necessidades públicas são providos por meio da cooperação entre os entes autárquicos e sendo muitos os entes e de diferentes estruturas em sentido de capacidades financeiras, geográficas e estratégicas, vários também são os tipos de cooperação que podem ser estabelecidos entre tais entidades.

As associaçóes de municípios atuam em áreas como o desenvolvimento económico, cultural e social, o planejamento territorial, o saneamento básico, educação e formação profissional, a organização e administração dos municípios, a gestão e proteção ambiental, todas as áreas voltadas para representação dos interesses dos municípios (FERNANDES, 2012).

A realização de cooperação entre aliados só é possível quando um acordo está devidamente estruturado, para que possa ser aprovado e aceito pelos atores participantes para então alcançar o poder necessário para realizar as atividades e os objetivos das alianças (KISLER, L.; HEIDMAN, 2006).

Os governos locais são atraídos por acordos voluntários de interjurisdição porque "permitem que eles aproveitem os recursos acumulados, coordenem melhor os esforços planejados e distribuam os riscos associados às emergências” (ANDREW, 2009, p. 382).

Para tanto, de acordo com o que salientam os autores, as alianças sobrevivem principalmente mediante a confiança mútua entre os parceiros e quando ninguém sente-se explorado ou enganado pelas outras partes envolvidas.

Portanto, uma cultura de confiança não é criada sozinha, mas ao longo do tempo e entre aqueles que se predispóem a participar e cooperar entre si, reduzindo por um lado as incertezas geradas pela novidade que a cooperação implica e por outro desenvolvendo a iniciativa e a ação.

É crível identificar, na literatura no que tange à Ação Coletiva Institucional, uma série de fatores contextuais que influenciam a motivação para cooperação, como as condiçôes fiscais dos municípios, as condiçôes econômicas, as características demográficas dos municípios e as características da aglomeração urbana onde estão inseridos.

As características fiscais tratam dos aspetos financeiros, relacionam-se com os recursos dos municípios e a necessidade de racionalização desses recursos para que mais e melhores serviços possam ser produzidos e prestados à população.

Para Krueger e McGuire (2005), os gestores públicos das comunidades que apresentam carga tributária elevada podem visualizar a cooperação como um meio de redução de custos.

Da mesma forma, ainda segundo os referidos autores, as cidades que possuem uma agenda agressiva para a provisão de serviços também estão interessadas na obtenção 
de recursos adicionais, e isto ocorre por meio da cooperação, podendo então realizar a concretização dos projetos propostos (KRUEGER, S.; MCGUIRE, 2005).

Porém, sabe-se que juntamente com as facilidades de cooperação, coexistem as dificuldades e os fatores que impossibilitam ou que tornam menos atrativas os possíveis acordos, também perfazem uma lista a ser considerada e estudada.

Há vários aspetos que podem dificultar a construção de formas de cooperação entre os entes públicos, uma vez que cada unidade administrativa governamental possui autonomia para realizar as demandas necessárias em sua respectiva autarquia e para juntar-se a outros quando não há condiçóes de sozinho supri-la, não sendo uma tarefa simples ou opção considerável para muitos administradores públicos, por diversas condicionantes como a perda da total autonomia nas decisóes dentre outros fatores.

Assim sendo, Abrucio et al. (2011) apontaram algumas variáveis desfavorecedoras da cooperação intermunicipal identificadas em suas pesquisas na área, sendo estas: o comportamento individualista e autárquico dos municípios; a ausência de uma identidade regional, acoplada ao baixo capital social das instituiçóes locais; as brigas políticopartidárias entre prefeitos ou entre os prefeitos com o governador; o engessamento do direito administrativo e de sua interpretação por parte dos Tribunais de Contas, criando obstáculos ao associativismo intermunicipal; a falta de indução federativa advinda dos outros níveis governamentais; a gestão pública frágil, o dificultando a obtenção de informação e conhecimento sobre a montagem de consórcios; os conflitos intergovernamentais em determinadas políticas públicas, como no caso da educação e seu ineficiente "regime de colaboração" e por fim a questão territorial e do associativismo (ABRUCIO, F. L.; SANO, H.; SYDOW, 2011, pp. 66-68).

Feiock (2009) acentua que a principal barreira à concretização de acordos de cooperação entre municípios são os denominados custos de transação, ou seja, os custos de coordenação (divisão e monitoramento de tarefas) e de negociação (divisão de custos e de benefícios) entre os potenciais parceiros.

Porém, em situação contrária, quando existir motivação para a efetivação dos acordos de cooperação, os baixos custos de transação facilitam a concretização de tais acordos. Quando os custos de transação forem elevados, o acordo se torna mais difícil ou inviável, pois a motivação deixa de existir.

Para grandes grupos, é mais difícil atingir os interesses coletivos sem um sistema adequado de incentivos à participação individual. Os custos individuais de participação podem suplantar os benefícios individuais, por isso se impóe a criação de um adequado sistema de incentivos à mobilização dos membros do grupo. E o resultado agregado obtido, muitas vezes, é inferior à quantidade necessária para ser um sistema eficiente de trabalho, devido a ação dos atores que retiram proveito de determinada situação sem que para ela tenham contribuído, razão na qual parece ser mais difícil a grupos de grande dimensão atingirem os seus objetivos coletivos (OSTROM, 1998). 


\subsection{Modelo de Investigação}

Seguindo o perfil dos fatores condicionantes e dificultadores da cooperação no âmbito da administração pública e de acordo com os estudos existentes na área, a presente pesquisa pretende aferir o conjunto de elementos já estudados e, bem assim, analisar se a realidade dos Municípios da CIM Região de Coimbra corrobora de forma total ou parcial a teoria subjacente, verificando a realidade atual dos municípios quanto à participaçáo em acordos de cooperação e em que nível de colaboração atual se encontram.

Com base no referencial teórico já apresentado, foram identificadas 3 macro-variáveis com o objetivo de aferir quais têm maior impacto na cooperação intergovernamental a nível local, e que se apresentam na figura seguinte (Figura 1).

Figura 1 - Modelo teórico Inicial

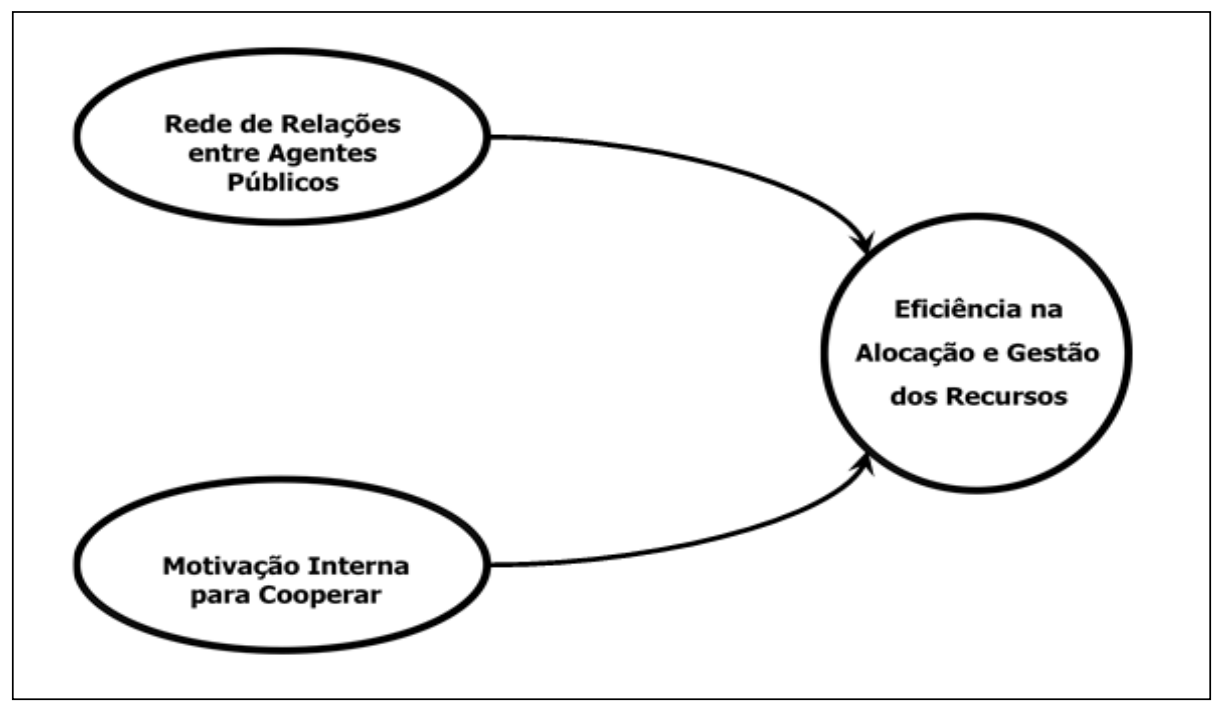

Fonte: autoria própria.

Para o modelo inicial (Figura 1), pretendeu-se apurar se as características das dimensões Rede de Relaçóes entre Agentes Públicos e Motivação Interna para Cooperar influenciam na Eficiência na Alocação e Gestão dos Recursos, para a cooperação intergovernamental a nível local.

\section{Metodologia}

Com este modelo pretendeu-se apurar se as características da dimensão Rede de Relações entre Agentes Públicos, influencia a Eficiência na Alocação e Gestão dos Recursos, tendo sido formulada a seguinte hipótese: $\mathrm{H} 1$ - A variável latente Rede de Relações entre Agentes Públicos tem impacto positivo direto na variável latente Eficiência na Alocação e Gestáo dos Recursos. Procedeu-se de igual forma para a variável Motivação Interna para Cooperar, formulando-se a seguinte hipótese: H2 - A variável latente Motivação Interna 
para Cooperar tem impacto positivo direto na variável latente Eficiência na Alocação e Gestão dos Recursos.

A metodologia teve como base o desenvolvimento de um inquérito por questionário online. Para tal utilizou-se o instrumento de criação de questionários google docs. $\mathrm{O}$ questionário foi composto por 34 questóes, e esteve online durante os dias 15 do mês de Junho do ano de 2018 até ao dia 11 do mês de Setembro do ano de 2018 (num total de 89 dias), no qual foi redirecionado para todos os municípios membros da CIM Regiáo Coimbra

No término da data limite de recebimento, obteve-se retorno de 62 respostas válidas, perfazendo uma média de 5 respondentes de cada um dos 19 municípios membros da CIM Região Coimbra e da Sede Administrativa, com uma média de retorno de 3,1 por cada um dos entes pertencentes a CIM Região de Coimbra.

$\mathrm{O}$ inquérito inicia com um conjunto de 5 questóes que permitem a caracterização da amostra pretendida.

As perguntas 6 a 9, relacionadas com a localização geográfica, e seguidamente a estas, foram formuladas as questóes 10 a 18, referentes as áreas de cooperação dos Municípios, seguindo-se para as as questóes 19 a 23, colher informaçóes acerca da eficiência da gestão e alocação dos recursos.

No que refere-se a rede de relações entre agentes públicos temos as questóes 24 a 32 e destas pretendeu-se colher informaçóes acerca dos acordos de cooperação existentes.

E como último quesito considerado, as questôes 33 e 34 abordaram a motivação interna para cooperar entre os municípios, estabelecendo padróes de facilitação na cooperação com uso de formação e capacitação sobre o tema.

Pretendeu-se que o respondente indicasse, com base em sua perceção a respeito dos acordos de cooperação com outros municípios membro da CIM, o seu nível de concordância ou discordância com os itens elencados no questionário, ora com base em itens como sim, não, não sei ou não respondo, da questão 06 à questão 18, e para as questôes 19 à questão 34 foi aplicada uma escala de likert.

Foram apuradas 62 respostas úteis, provenientes de 19 Municípios da Região de Coimbra.

Das 62 respostas úteis obtidas, 33 (52,5\%) são do sexo feminino e as restantes 29 $(47,5 \%)$ do sexo masculino. A média de idades dos respondentes entre 36 e 50 anos (grupo de idade máxima acima de 51 anos e idade mínima de 25 a 35 anos.

\section{Resultados e discussóes}

Perfazendo uma média entre os que afirmam possuir conhecimento de que o município no qual trabalham possuem acordos de cooperação com outros municípios além dos membros da CIM Região Coimbra, entre outras CIM da Região e ou outros municípios não vizinhos, obteve-se uma média de $70,4 \%$ dos respondentes que estão cientes desses acordos por meio de formas diversas. 
Quando analisado o nível de informação acerca das áreas específicas em que os municípios realizam os acordos de cooperação, foram elencados no inquérito as áreas de Administração e Gestão, Infraestruturas e Urbanismo, Desenvolvimento Econômico, Desenvolvimento Social, Educação, Saúde, Desporto, Cultura e Ambiente, e obteve-se uma média geral de $51 \%$ no índice de informação entre os respondentes acerca dos acordos efetuados em seus municípios.

Após a análise da parte introdutória do inquérito realizado, segue-se a parte específica dos blocos onde pretendeu-se identificar quais os fatores de cooperação possuem maior índice de condicionantes e quais são elencados como fatores dificultadores de cooperaçáo, sendo analisado através da Figura 2.

$\mathrm{Da}$ análise da figura 2 concluímos que das 3 variáveis latentes em estudo todas oferecem significância estatística para um nível de confiança de 95,00\% $(0,9500)$. É também possível aferir as avaliações médias das variáveis. Para a variável "Rede de relaçóes entre agentes públicos" - com a avaliaçấo média mais alta - o valor obtido foi de 5,5 pontos, seguida da variável "Motivação interna para cooperar" com uma avaliação média de 5,4 pontos.

$\mathrm{Na}$ mesma linha surge a variável dependente, "Eficiência na alocação e Gestão dos recursos" que apresenta um valor médio também favorável para as percepçóes, correspondendo a 6,1 pontos.

Figura 2 - Modelo Final

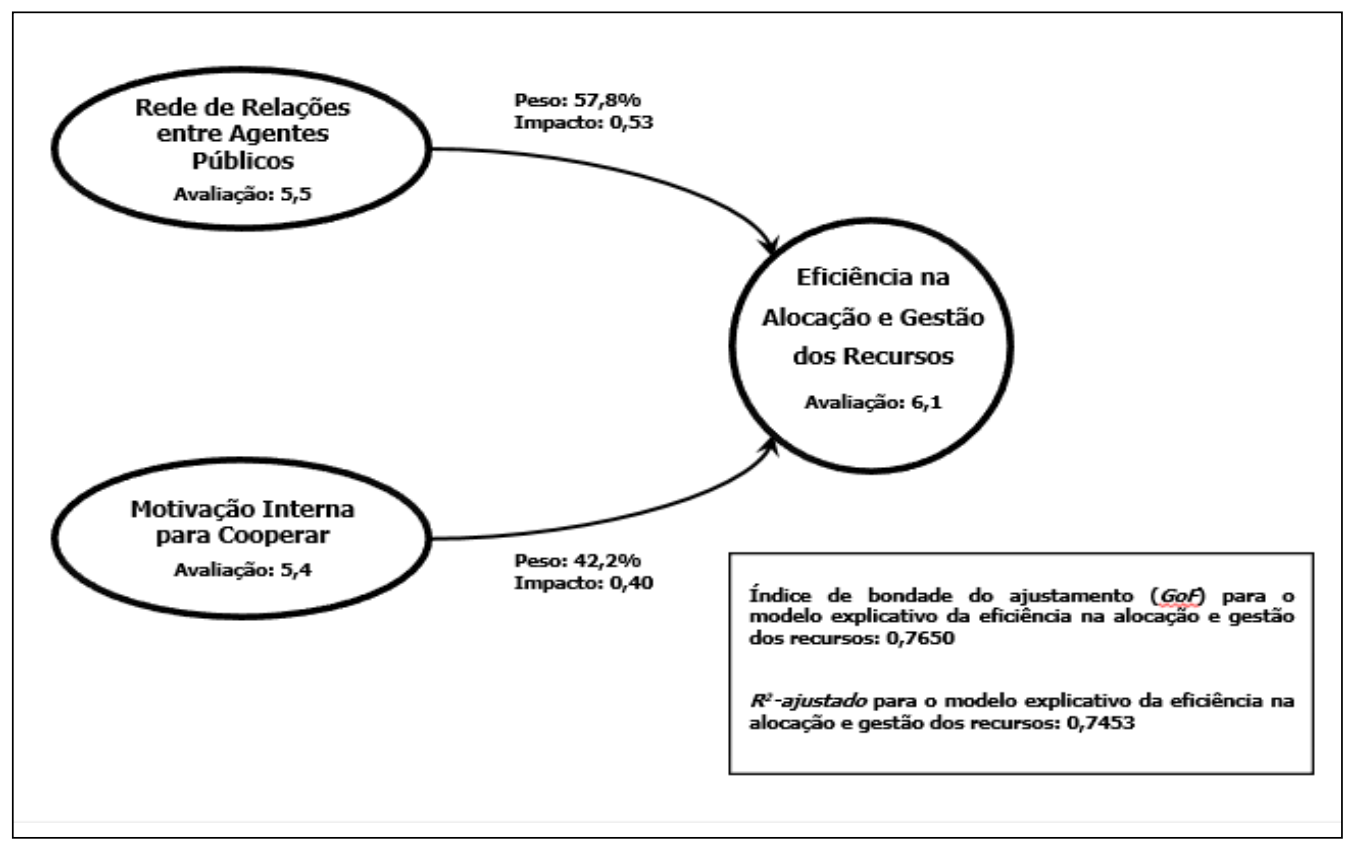

Fonte: autoria própria. 
Da observação dos resultados apresentados no modelo de percepçóes obtido (Figura 2) constata-se que para um nível de significância de 0,05 , o aumento de 1 ponto na avaliação média da dimensão Rede de relaçóes entre agentes públicos, teria um impacto de 0,53 pontos na dimensão Eficiência na alocação e Gestão dos recursos. Já no âmbito da dimensão Motivação interna para cooperar, o aumento de 1 ponto na sua classificação média teria um impacto de 0,40 na dimensão Eficiência na alocação e Gestão dos recursos.

A dimensão que apresenta maior peso nas percepções dos respondentes é a dimensão Rede de relaçóes entre agentes públicos, contribuindo com $57,80 \%$, seguida da dimensão Motivação interna para cooperar com um peso de $42,2 \%$.

É possível verificar que as percepções médias das variáveis latentes independentes com significância estatística são favoráveis uma vez que são sempre superiores a 5 pontos em 10 possíveis, oscilando entre um valor mínimo de 5,4 pontos, relativo à dimensão "Motivação interna para cooperar", e um valor máximo de 5,5 pontos, relativo a dimensão "Rede de relaçóes entre agentes públicos”.

Por fim, o modelo proposto apresenta um coeficiente de determinação ajustado de $74,53 \%$ o que significa que as variáveis latentes independentes explicam 74,53\% da variação da variável dependente "Eficiência na alocação e Gestão dos recursos".

Quanto ao índice de bondade do, - índice que procura validar globalmente o modelo de equaçóes estruturais - os valores obtidos são globalmente aceitáveis.

\section{Consideraçóes finais}

O presente estudo teve como principal objetivo aferir a percepção dos trabalhadores dos municípios da Comunidade Intermunicipal da Região de Coimbra, sobre quais os fatores/ determinantes que estão na base da criação de relaçóes de cooperação intergovernamental ao nível local.

Ao nível dos resultados, o modelo de equaçóes estruturais (Figura 2) revela coeficientes de impacto estatisticamente significativos para níveis de significância de 0,05 para as variáveis latentes em estudo.

Ao término da análise realizada por meio da aplicação do modelo de equaçóes estruturais (SEM - Structured Equation Modeling), concluímos que das variáveis latentes em estudo foram confirmadas todas as hipóteses, sendo que da análise à capacidade de ajuste do modelo conclui-se que este é aceitável. Deste modo, é possível afirmar que as percepçôes dos respondentes acerca das variáveis latentes "Motivação interna para cooperar" e "Rede de relações entre agentes públicos" tem impacto direto e positivo nas suas percepções relativamente à "Eficiência na alocação e Gestão dos recursos".

Na concepção da Ação Coletiva Institucional, a motivação é uma condição necessária, porém não suficiente para a efetivação de acordos cooperativos entre municípios sendo estes fatores confirmados por Krueger e McGuire (2005, p. 2), quando frisam que a variabilidade do comportamento cooperativo entre municípios "sugere que a decisão de cooperar envolve outros fatores além da motivação subjacente à economia de recursos” e os resultados são claros para o quesito motivação interna e comunicação entre os colaboradores das entidades 
públicas, haja vista os resultados obtidos com a aplicação do inquérito que reforçam estes dados.

Para Kettunen e Teles (2015, p. 1), a cooperação intermunicipal "é um tipo de organizaçáo de rede que funciona em um contexto administrativo político local”, e se caracteriza por uma troca de interesses entre os participantes, para tanto, uma ampla de rede de relacionamentos entre os municípios que possuem necessidades comuns.

Os trabalhadores que afirmaram possuir informaçóes relativas aos acordos de cooperação com outros municípios além dos membros da CIM - Região Coimbra, entre outras CIM da Região e/ou outros municípios não vizinhos, abrange uma média geral de $70,4 \%$ dos respondentes. Estes resultados encontram-se alinhados com a bibliografia, sendo exemplo desse alinhamento a perspetiva de Feiock (2009) ao afirmar que os municípios vizinhos têm incentivos para cooperar com base nos custos técnicos de compartilhamento de serviços, uma vez que para serviços com altos custos de transação, podemos esperar que um acordo seja solicitado com o mesmo vizinho em diferentes serviços.

Já da análise do nível de informação acerca das áreas específicas em que os municípios realizam os acordos de cooperação, obteve-se uma média geral de $51 \%$ no índice de informação entre os respondentes acerca dos acordos efetuados em seus respetivos municípios.

Os dados demonstram portanto, um índice superior a 60\% no nível de disseminação da informaçấo, interesse e envolvimento dos trabalhadores dos entes públicos para com a boa prestação e execução dos acordos de cooperação que objetivam a boa governação pública em esfera local.

Estes dados demonstram o que apregoam Kettunen e Teles (2015, p. 1), quando afirmam que a cooperação se caracteriza por uma "troca de interesses entre os participantes e fatores como o tamanho ou os recursos insuficientes para prestar serviços ou cumprir obrigaçóes é um dos fatores contribuintes para tal processo".

Os resultados obtidos na presente pesquisa corroboram com o que admoesta Feiock (2009) ser o objetivo central dos governos, uma vez que para a resoluçáo de problemas coletivos, deve-se da mesma forma, pensar coletivamente, e iniciar açóes de forma local e específica para atingir resultados locais e de amplitude maior quando pensamos que vários municípios estarão participando de forma conjunta.

Ainda tem-se como confirmação das definições sobre o assunto, o que diz Niero (2011, p. 45), quando este reforça que "a junção dos esforços individuais para o resultado coletivo de eficiência e efetividade nos serviços e obras públicas tem-se mostrado ser de absoluta mais valia”.

No tocante a motivação, Ansell e Gash (2008, p. 546),=discorrem que "o sucesso da governação depende da capacidade do governo e do setor público em implicar e comprometer todos os parceiros pertinentes numa tomada de decisão consensual" e o objetivo fim deve ser à promoção da ação coletiva em busca de fins comuns, e esse fator é bastante evidente quando se trata de um esforço coletivo onde a participação ativa de todos os envolvidos é de extrema importância para os resultados. 
No entanto, apesar dos resultados terem sidos significativos para o problema inicialmente proposto, importa referir que o modelo desenvolvido no presente estudo, poderá ser melhorado em termos da sua robustez com o contributo resultante da introduçáo de outras dimensões que poderão oferecer melhorias ao nível da qualidade do modelo.

Como oportunidades de investigação futura, seria potencialmente interessante realizar uma nova aplicação do inquérito para recebimento de uma amostra quantitativamente superior para um resultado mais apurado com maior amplitude de informaçóes e segurança nos dados e resultados obtidos, englobando outras CIM da Região para um estudo mais alargado sobre a percepção dos trabalhadores a nível regional ou do país.

\section{Referências}

ABRUCIO, F. L.; SANO, H.; SYDOW, C. T. Radiografia do associativismo territorial brasileiro: tendências, desafios e impactos sobre as regióes metropolitanas. São Paulo: Annablume, 2011.

ABRUCIO, F. L.; FILIPPIM, E. S.; DIEGUEZ, R. C. Inovação na cooperação intermunicipal no Brasil: a experiência da Federação Catarinense de Municípios (Fecam) na construção de consórcios públicos. Revista de Administraçáo Pública, v. 47, n. 6, p. 1543-1568, 2013.

AFONSO, M. M.; FERNANDES, A. P. AbCD-Introduçáo à Cooperaçáo para o Desenvolvimento. Lisboa: Instituto Marquês de Valle Flôr e OIKOS - Cooperação e Desenvolvimento, 2005.

AFONSO, M. M. Cooperaçáo para o desenvolvimento: Características, evoluçáo e perspectivas futuras. Lisboa: CIDAC, D. L, 1996.

ANDREW, S. A. Regional Integration Through Contracting Networks. Urban Affairs Review, v. 44, n. 3, p. 378-402, 7 Jan. 2009.

ANSELL, C.; GASH, A. Collaborative governance in theory and practice. Journal of Public Administration Research and Theory, v. 18, n. 4, p. 543-571, 2008.

BILHIM, J. A. F. Nova governação pública e meritocracia. Sociologia, Problemas e Práticas, v. 84, n. 9, 2017.

FEIOCK, R. C.; SCHOLZ, J. T. Self-organizing Federalism: Collaborative Mechanisms to Mitigate Institutional Collective Action Dilemmas. Public Administration, v. 91, n. 2, p. 506-520, 2013.

FEIOCK, R. C. Rational choice and regional governance. Journal Urban Affairs Review, v. 29, n. 1, p. 47-63, 2007.

FEIOCK, R. C. Metropolitan Governance and Institutional Collective Action. Urban Affairs Review, v. 44, n. 3, p. 356-377, 7 Jan. 2009. 
FERNANDES, M. J. R. Cooperaçáo descentralizada e intermunicipal: acordos de cooperaçáo no distrito Vila Real como fator de desenvolvimento local. Vila Real: Universidade de Trás os Montes e Alto Douro, 2012.

GULATI, R.; SINGH, H. The architecture of cooperation: Managing coordination costs and appropriation concerns in strategic alliances. Administrative Science Quarterly, v. 43, n. 4, p. 781-814, 1998.

HAWKINS, C. V. Local economic development joint ventures and metropolitan networks. Public Administration Quarterly, v. 35, n. 1, p. 59-92, 2011.

HECKATHORN, D. D.; STEVEN, M. M. Bargaining and constitutional contracts. American Journal of Political Science, v. 31, n. 1, p. 142-168, 1987.

HULST, R., VAN MONTFORT, A., HAVERI, A., AIRAKSINEN, J.; KELLY, J. Institutional shifts in inter-municipal service delivery. Public Organization Review, v. 9, n. 3, p. 263-285, 2009.

KETTUNEN, P.; TELES, F. Municipal Cooperation: A Review of the Reasons and Results. PSA 65th International Conference. Anais...Sheffield: 2015

KISLER, L.; HEIDMAN, F. G. Governança pública: novo modelo regulatório para as relaçôes entre Estado, mercado e sociedade? Revista Administração Pública - RAP, v. 40, n. 3, p. 479-99, 2006.

KRUEGER, S.; MCGUIRE, M. A transaction costs explanation of interlocal government collaboration. Eighth National Public Management Research Conference. Anais...Los Angeles: 2005

LYNN JR, L. E., HEINRICH, C. J., \& HILL, C. J. Studying governance and public management: Challenges and prospects. Journal of Public Administration Research and Theory, v. 10, n. 2, p. 233-262, 2000.

MORGAN, D. R.; HIRLINGER, M. W. Intergovernmental service contracts: A multivariate explanation. Urban Affairs Quarterly, v. 27, n. 1, p. 128-144, 1991.

NIERO, J. C. C. Gestão das relaçóes intergovernamentais: fatores condicionantes da propensáo a cooperar por parte dos governos locais. [s.l.] Universidade de São Caetano do Sul, 2011.

OSTROM, M. A behavioral approach to the rational choice theory of collective action: Presidential Address, American political Science Association. The American Political Science Review, v. 92, n. 1, p. 1-22, 1998.

RODRIGUEZ, E. R. El rol de los gobiernos locales en los mecanismos de coordinación intergubernamental. VII Congreso Internacional del CLAD sobre la Reforma del Estado y de La Administración Pública. Anais...Lisboa: 2002. 